International Journal of

Molecular Sciences

ISSN 1422-0067

www.mdpi.com/journal/ijms

Article

\title{
An Imprinted Cross-Linked Enzyme Aggregate (iCLEA) of Sucrose Phosphorylase: Combining Improved Stability with Altered Specificity
}

\section{Karel De Winter, Wim Soetaert and Tom Desmet *}

Centre of Expertise for Industrial Biotechnology and Biocatalysis, Department of Biochemical and Microbial Technology, Faculty of Biosciences Engineering, Ghent University, Coupure Links 653, Ghent B-9000, Belgium; E-Mails: karel.dewinter@ugent.be (K.D.W.); wim.soetaert@ugent.be (W.S.)

* Author to whom correspondence should be addressed; E-Mail: t.desmet@ugent.be; Tel.: +32-9-2649-920; Fax: +32-9-2646-032.

Received: 28 August 2012; in revised form: 5 September 2012 / Accepted: 5 September 2012 / Published: 11 September 2012

\begin{abstract}
The industrial use of sucrose phosphorylase (SP), an interesting biocatalyst for the selective transfer of $\alpha$-glucosyl residues to various acceptor molecules, has been hampered by a lack of long-term stability and low activity towards alternative substrates. We have recently shown that the stability of the SP from Bifidobacterium adolescentis can be significantly improved by the formation of a cross-linked enzyme aggregate (CLEA). In this work, it is shown that the transglucosylation activity of such a CLEA can also be improved by molecular imprinting with a suitable substrate. To obtain proof of concept, SP was imprinted with $\alpha$-glucosyl glycerol and subsequently cross-linked with glutaraldehyde. As a consequence, the enzyme's specific activity towards glycerol as acceptor substrate was increased two-fold while simultaneously providing an exceptional stability at $60{ }^{\circ} \mathrm{C}$. This procedure can be performed in an aqueous environment and gives rise to a new enzyme formulation called iCLEA.
\end{abstract}

Keywords: sucrose phosphorylase; immobilization; imprinting; CLEA; glucosyl glycerol

\section{Introduction}

Sucrose phosphorylase (SP) catalyzes the reversible phosphorolysis of sucrose into $\alpha$-D-glucose 1-phosphate $(\alpha \mathrm{G} 1 \mathrm{P})$ and D-fructose. Although it is formally classified as a glycosyl transferase 
(EC 2.4.1.7), the enzyme belongs to glycoside hydrolase family 13 [1] and follows the typical double displacement mechanism of retaining glycosidases [2]. The crystal structure of the enzyme from Bifidobacterium adolescentis has been determined and consists of a $(\beta / \alpha)_{8}$ barrel containing Asp192 (nucleophile) and Glu232 (acid/base) as catalytic residues [3]. Thanks to its broad acceptor specificity, SP can be employed for the transfer of glucose to a wide variety of carbohydrates as well as non-carbohydrate molecules [4]. For example, an exceptionally efficient process for the production of $\alpha$-glucosyl glycerol $(\alpha \mathrm{GG})$ has been developed with SP $[5,6]$. The product is a moisturizing agent for cosmetics and is commercially available under the tradename Glycoin ${ }^{\circledR}$.

Unfortunately, the use of SP as industrial biocatalyst has been limited by a lack of long-term stability and low activity on alternative substrates [7,8]. Very recently, however, significant improvements in the thermostability of the SP from B. adolescentis have been realized by immobilization on Sepabeads [9], formation of a cross-linked enzyme aggregate (CLEA) [10,11] and introduction of specific mutations [12]. In contrast, an enzyme with a modified specificity has not yet been reported, although studies aiming to alter the acceptor specificity of SP by protein engineering have revealed insight into the glycosylation mechanism [13] and succeeded to suppress the hydrolytic activity without affecting the ability of phenolic compounds to act as acceptor [14].

Molecular imprinting is an attractive alternative to mutagenesis for the manipulation of enzymatic properties [15]. Indeed, the three-dimensional structure of a protein can be modified by noncovalent interactions with an imprinting molecule in mild denaturing conditions [16]. Unfortunately, imprinted enzymes are only able to maintain their new conformation when transferred to a non-aqueous environment or when immobilized by cross-linking [17,18]. For the latter strategy, a radical polymerization procedure has been reported that requires transfer to organic solvents and derivatization of the enzyme [19-21].

In this work, we describe the molecular imprinting of the SP from Bifidobacterium adolescentis using cross-linking by glutaraldehyde [11] instead of radical polymerization in pure organic solvents. Indeed, the use of an aqueous environment yields a considerably simpler imprinting procedure resulting in an imprinted cross-linked enzyme aggregate (iCLEA) exhibiting altered acceptor specificity as well as excellent stability at $60^{\circ} \mathrm{C}$.

\section{Results and Discussion}

\subsection{Production of the iCLEA}

For the preparation of the imprinted cross-linked enzyme aggregate (iCLEA), the thermostable variant LNFI of the SP from B. adolescentis has been used [12]. The enzyme was recombinantly expressed in E. coli and partially purified by means of a heat treatment, which has been shown to remove the contaminating phosphatase activity [10]. The next steps in the preparation of the iCLEA then consist of imprinting, followed by precipitation (Figure 1). 
Figure 1. General scheme for the production of imprinted cross-linked enzyme aggregates (iCLEAs).

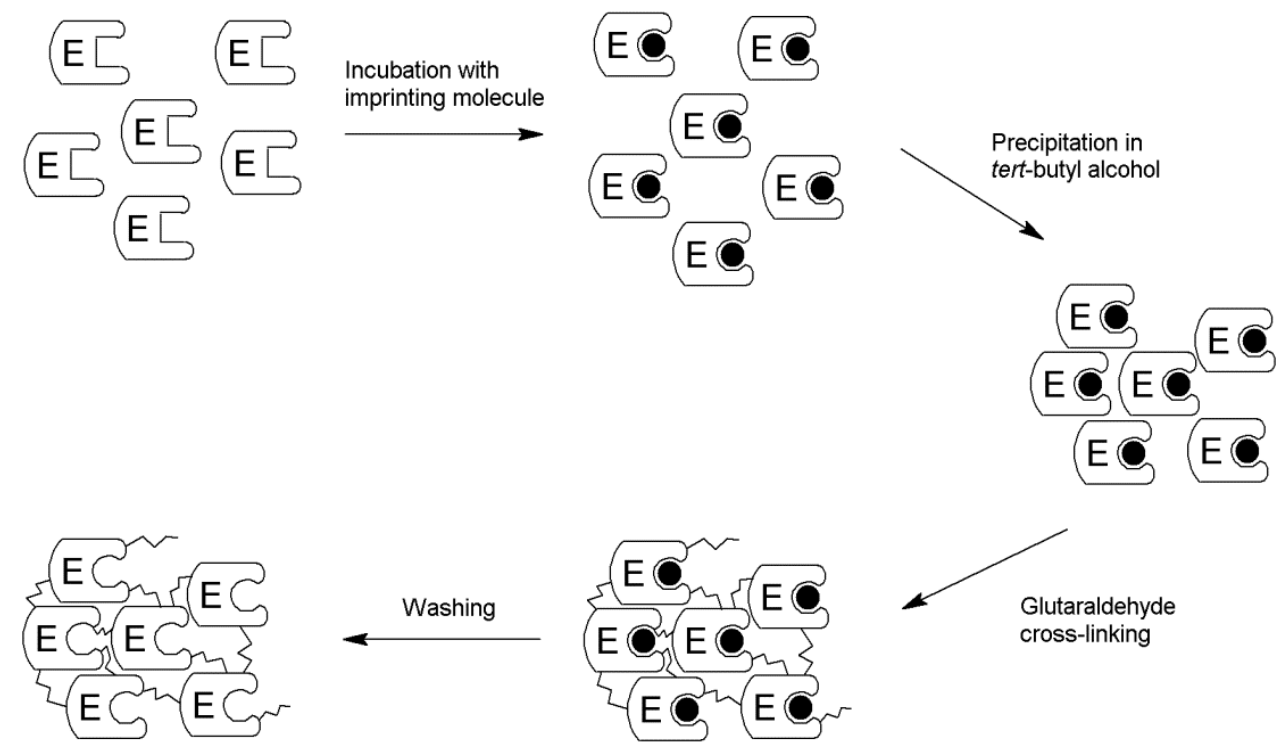

To that end, the precipitation of SP in the presence of a number of possible imprinting molecules was first evaluated (Table 1). Previous research has identified tert-butyl alcohol as the precipitant of choice [10]. However, the presence of phosphate or $\alpha-G 1 P(100-500 \mathrm{mM})$ resulted in the appearance of a second phase upon addition of tert-butyl alcohol, excluding these molecules from use as imprinters. Also, addition of sucrose in a concentration higher than $200 \mathrm{mM}$ was found to inhibit the precipitation of SP, whereas glycerol and $\alpha \mathrm{GG}$ did not affect precipitation. Clearly, these results indicate the importance of evaluating precipitation thoroughly, prior to the production of an iCLEA.

Table 1. Precipitation of sucrose phosphorylase (SP) in the presence of different imprinting molecules. Precipitation was achieved by adding $6 \mathrm{~mL}$ tert-butyl alcohol to $4 \mathrm{~mL}$ enzyme solution under agitation at $4{ }^{\circ} \mathrm{C}$.

\begin{tabular}{cccc}
\hline Imprinting molecule & {$[\mathbf{C}]^{\mathbf{a}} \mathbf{( M )}$} & Precipitation $\mathbf{( \% )}$ & $\mathbf{S P}_{\text {residual }}{ }^{\mathbf{b}} \mathbf{( \% )}$ \\
\hline None & $/$ & 97.8 & 1.2 \\
Sucrose & 0.2 & 96.4 & 1.6 \\
Sucrose & 0.5 & 52.1 & 38.5 \\
Sucrose & 1 & 40.6 & 56.8 \\
Glycerol & 0.5 & 98.2 & 1.1 \\
Glycerol & 1 & 96.6 & 1.3 \\
Glycerol & 2 & 97.6 & 1.4 \\
sucrose + glycerol & $0.5+2$ & 68.9 & 25.6 \\
sucrose + glycerol & $0.2+2$ & 96.6 & 1.5 \\
$\alpha G G$ & 0.2 & 97.3 & 1.4 \\
$\alpha G G$ & 1 & 96.4 & 1.2 \\
\hline \multicolumn{2}{c}{${ }^{a}$ of the imprinting molecules; ${ }^{b}$ after precipitation. }
\end{tabular}

Finally, the aggregated enzyme molecules were chemically cross-linked with glutaraldehyde to obtain the corresponding immobilizates. A typical immobilization yield of $30 \%$ has been reported for 
SP [10], and this value is also obtained in the presence of glycerol or $\alpha \mathrm{GG}$. However, the addition of sucrose during precipitation was found to increase the immobilization yield by roughly $10 \%$. This result is in accordance with work published by Wang and collaborators, who reported a sugar-assisted precipitation strategy to increase the activity of a Penicillin G Acylase CLEA [22].

The specificity of the obtained formulations was then examined and compared with that of a non-imprinted CLEA. More specifically, their activity towards phosphate (phosphorolysis) and glycerol (transglucosylation) as acceptor was determined. Imprinting with sucrose, glycerol or a combination of both was found to have no influence on the specificity of the enzyme preparation (Figure 2). However, initiating aggregation and cross-linking after $30 \mathrm{~min}$ incubation with sucrose and glycerol did significantly increase the transglucosylation activity. This must mean that the presence of glycosylated product is required to modify the enzyme's acceptor specificity. Indeed, imprinting with $200 \mathrm{mM} \alpha \mathrm{GG}$ almost doubled the specific activity on glycerol, from $2.22 \mathrm{U} / \mathrm{mg}$ for the non-imprinted CLEA to $4.12 \mathrm{U} / \mathrm{mg}$ for the iCLEA. Increasing the $\alpha \mathrm{GG}$ concentration to $1 \mathrm{M}$ during imprinting. However, it did not significantly improve the acceptor specificity much further.

Figure 2. Transglucosylation/phosphorolysis ratio for different CLEA formulations. ${ }^{a}$ Cross-linking was initiated upon addition of the imprinting molecules; ${ }^{b}$ Cross-linking was initiated after $30 \mathrm{~min}$ incubation; ${ }^{\mathrm{c}} 200 \mathrm{mM} \alpha$-glucosyl glycerol $(\alpha \mathrm{GG})$ was used; d $1 \mathrm{M} \alpha \mathrm{GG}$ was used.

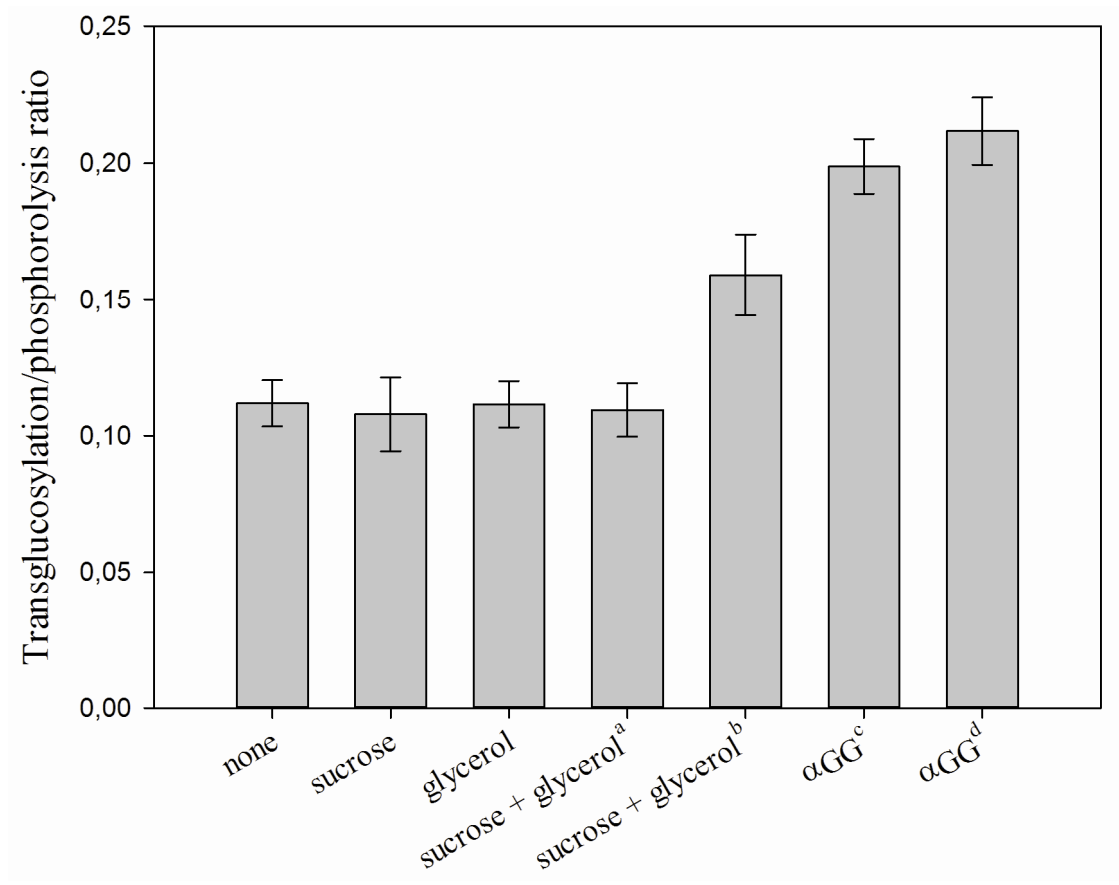

\subsection{Characterization of the iCLEA}

When SP is used for transglucosylation reactions, both primary and secondary hydrolysis can decrease the atom economy [4,23]. Although $\alpha \mathrm{GG}$ itself is a very poor substrate, hydrolysis of sucrose can be quite significant and even lead to the formation of inhibiting products $[5,24]$. Therefore, the hydrolytic activity of the CLEA and iCLEA were examined in the presence of sucrose and glycerol as 
substrates. Hydrolysis was found to be identical for both biocatalysts, meaning that the ratio with transglucosylation is only half as high for the iCLEA than for the CLEA.

To further asses its applicability in carbohydrate conversions, the thermostability of the iCLEA preparation was evaluated by incubation at $60{ }^{\circ} \mathrm{C}$ and measuring the residual activity at several points in time (Figure 3). The iCLEA was found to exhibit a comparable thermostability to the non-imprinted CLEA, and thus to be drastically more stable than the soluble enzyme. Indeed, an impressive $75 \%$ of the initial activity was still present after three weeks incubation at $60{ }^{\circ} \mathrm{C}$. Next, the efficiency of the newly formed iCLEA was demonstrated by comparing its performance with that of the reference CLEA in a batch production of $\alpha \mathrm{GG}$ at $60^{\circ} \mathrm{C}$ (Figure 4). This clearly showed that the maximal transfer yield of $84 \%$ [5] could be reached twice as fast with the iCLEA than with its non-imprinted counterpart. Furthermore, the newly formed iCLEA also proved its excellent operational stability by losing no activity whatsoever during five consecutive batch conversions (data not shown).

Figure 3. Stability of different SP formulations at $60{ }^{\circ} \mathrm{C}$. The residual activity of soluble SP $(\bullet)$, CLEAs (०) and iCLEAs ( $\boldsymbol{\nabla})$ was measured every $24 \mathrm{~h}$.

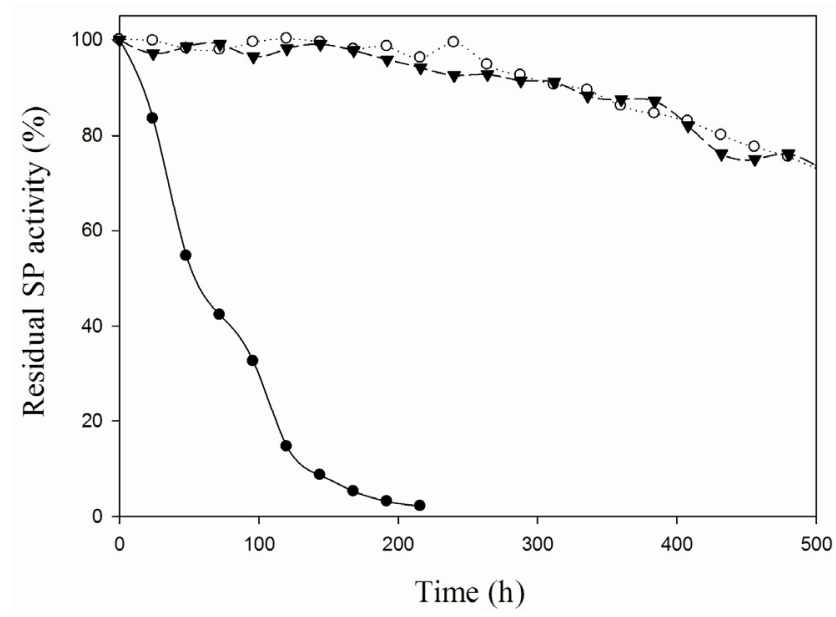

Figure 4. Synthesis of $\alpha \mathrm{GG}$ with immobilized SP at $60{ }^{\circ} \mathrm{C}$. The conversions were performed with $5 \mathrm{mg} / \mathrm{mL}$ CLEAs (०) or iCLEAs $(\bullet)$ in a $50 \mathrm{mM}$ MOPS buffer $\mathrm{pH} 7$ containing $800 \mathrm{mM}$ sucrose and $2 \mathrm{M}$ glycerol.

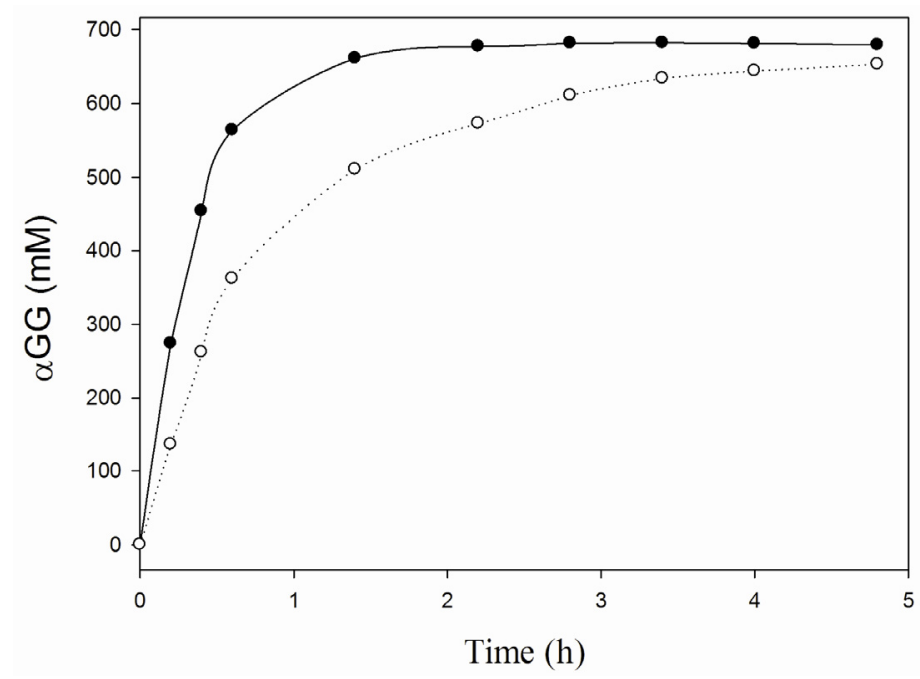




\section{Experimental Section}

\subsection{Materials}

Glucosyl glycerol $(\alpha \mathrm{GG})$ was produced as previously described [5]. Tert-butyl alcohol, glutaraldehyde, and sodium borohydride were purchased from Aldrich-Chemie (Bornem, Belgium), Fisher (Erembodegem, Belgium) and Acros (Geel, Belgium), respectively. All other reagents were analytical grade and purchased from Sigma-Aldrich.

\subsection{Enzyme Production and Purification}

E. coli XL10-Gold cells were used for transformation with the constitutive expression plasmid pCXshP34_BaSP_LNFI [12,25]. The resulting strain was routinely grown at $37{ }^{\circ} \mathrm{C}$ on $50 \mathrm{~mL} \mathrm{LB}$ medium (10 g tryptone/L, $5 \mathrm{~g}$ yeast extract/L, $5 \mathrm{~g} \mathrm{NaCl} / \mathrm{L} ; \mathrm{pH} 7.0)$ supplemented with $100 \mathrm{mg} / \mathrm{L}$ ampicillin. After overnight growth, the culture was inoculated into $1 \mathrm{~L}$ of double LB medium (20 g tryptone/L, $10 \mathrm{~g}$ yeast extract/L, $5 \mathrm{~g} \mathrm{NaCl} / \mathrm{L} ; \mathrm{pH} 7.0$ ) supplemented with $30 \mathrm{~g} / \mathrm{L}$ glucose in a $2 \mathrm{~L}$ Biostat $\mathrm{M}$ reactor (B. Braun Biotech Inc., Allentown, PA, USA). Fermentation was done at $37{ }^{\circ} \mathrm{C}$ and $550 \mathrm{rpm}$ with aeration at $1.2 \mathrm{vvm}$. When necessary, anti-foam was added manually to prevent foaming. After approximately $8 \mathrm{~h}$ of growth $\left(\mathrm{OD}_{600}\right.$ was 22$)$, the cells were harvested by centrifugation (7000 rpm, $4{ }^{\circ} \mathrm{C}, 20 \mathrm{~min}$ ). The obtained pellets were frozen at $-20{ }^{\circ} \mathrm{C}$ until further use.

Cell extracts were prepared by treatment of frozen pellets with $50 \mathrm{mM}$ MOPS pH 7 supplemented with $100 \mathrm{mg} / \mathrm{mL}$ lysozyme for $30 \mathrm{~min}$ at room temperature, followed by $2 \times 2 \mathrm{~min}$ sonification (Branson 250 Sonifier, level 3, 50\% duty cycle). Subsequently, cell debris was removed by centrifugation $\left(12,000 \mathrm{rpm}, 4{ }^{\circ} \mathrm{C}, 30 \mathrm{~min}\right)$. Finally, the crude enzyme preparation was heat-purified by incubation at $60{ }^{\circ} \mathrm{C}$ for $60 \mathrm{~min}$ as described previously [10].

\subsection{Preparation of the iCLEA}

The heat-purified SP enzyme was diluted to a final protein concentration of $2 \mathrm{mg} / \mathrm{mL}$ and allowed to react with the imprinting molecules for $30 \mathrm{~min}$ at $37^{\circ} \mathrm{C}$. Next, $6 \mathrm{~mL}$ of tert-butanol was added to $4 \mathrm{~mL}$ of the imprinted SP solution under agitation. After $30 \mathrm{~min}, 1.36 \mathrm{mg}$ glutaraldehyde was gently added to cross-link the enzyme aggregate, and the mixture was kept under stirring for $60 \mathrm{~min}$. Reduction of the formed imine bonds was achieved by adding $10 \mathrm{~mL}$ of a solution containing $1 \mathrm{mg} / \mathrm{mL}$ sodium borohydride in $0.1 \mathrm{M}$ sodium bicarbonate buffer at $\mathrm{pH} 10$. After $15 \mathrm{~min}$, another $10 \mathrm{~mL}$ was added and allowed to react for $15 \mathrm{~min}$. Finally, the iCLEA was harvested by centrifugation $\left(12,000 \mathrm{rpm}, 4^{\circ} \mathrm{C}, 30 \mathrm{~min}\right)$ and washed five times with $50 \mathrm{mM}$ MOPS buffer at $\mathrm{pH} 7$. All steps were performed in a thermoshaker (Eppendorf) at $750 \mathrm{rpm}$ and $4{ }^{\circ} \mathrm{C}$. The immobilization yield is defined as the ratio of the activity detected in the iCLEA preparation to that present in the original enzyme solution.

\subsection{Activity Assays}

Phosphorolysis of sucrose was measured discontinuously with an enzymatic assay, in which the production of $\alpha \mathrm{G} 1 \mathrm{P}$ is coupled to the reduction of $\mathrm{NAD}^{+}$in the presence of phosphoglucomutase and glucose-6-phosphate dehydrogenase [26]. The reactions were analyzed by inactivation of samples 
$\left(5 \mathrm{~min}\right.$ at $95{ }^{\circ} \mathrm{C}$ ) at regular intervals, followed by measurement of the absorbance at $340 \mathrm{~nm}$ in a microplate reader 680XR (Bio-Rad; Nazareth, Belgium). One unit of phosphorolysis activity corresponds to the release of $1 \mu \mathrm{mol}$ fructose from $100 \mathrm{mM}$ sucrose in $100 \mathrm{mM}$ phosphate buffer at $\mathrm{pH} 7$ and $37^{\circ} \mathrm{C}$.

The transglucosylation activity of SP towards glycerol was determined indirectly by measuring the increase in reducing sugars. More specifically, the release of fructose (and glucose) from sucrose as donor substrate was determined discontinuously with the bicinchonic acid (BCA) method [27]. In parallel, the release of glucose through hydrolysis was determined discontinuously with the glucose oxidase/peroxidase assay [28]. When glucose was detected, its concentration was subtracted twice from the concentration of reducing sugars measured with the BCA method, to calculate the net transglucosylation activity. One unit of transglucosylation activity corresponds to the production of $1 \mu \mathrm{mol} \alpha \mathrm{GG}$ from $800 \mathrm{mM}$ sucrose and $2 \mathrm{M}$ glycerol in $50 \mathrm{mM}$ MOPS buffer at $\mathrm{pH} 7$ and $60{ }^{\circ} \mathrm{C}$. Alternatively, the concentration of $\alpha \mathrm{GG}$ was determined directly by HPLC analysis using an aminex HPX-87C column (Bio-Rad) with milliQ water as the mobile phase at a constant flow rate of $0.6 \mathrm{~mL} / \mathrm{min}$ and $85{ }^{\circ} \mathrm{C}$. The hydrolytic activity was quantified using $50 \mathrm{mM}$ donor and $65 \mathrm{mM}$ acceptor, which is identical to the conditions used to assess the transglucosylation potential of SP [8]. Protein concentrations were measured according to the Lowry method [29], using bovine serum albumin as standard. Unless otherwise stated, all experiments were performed in triplicate and had a CV of less than $10 \%$.

\subsection{Stability Assays}

The thermostability of the iCLEA was determined by incubation in $50 \mathrm{mM}$ MOPS buffer $\mathrm{pH} 7$ in a water bath at $60^{\circ} \mathrm{C}$. Every $24 \mathrm{~h}$, samples were inactivated and the residual activity was analyzed using the BCA method. In addition, the operational stability was evaluated by using the iCLEA for consecutive batch conversions of $800 \mathrm{mM}$ sucrose and $2 \mathrm{M}$ glycerol at $60{ }^{\circ} \mathrm{C}$. After each reaction, the iCLEA were recuperated by centrifugation $\left(12,000 \mathrm{rpm}, 4{ }^{\circ} \mathrm{C}, 30 \mathrm{~min}\right)$ and washed three times with $50 \mathrm{mM}$ MOPS buffer at $\mathrm{pH} 7$.

\section{Conclusions}

Although molecular imprinting of a cross-linked enzyme aggregate (iCLEA) has been described for improving the activity of the hydroxynitrile lyase from Linum usitatissimum [30], this is the first time it has been used to alter the transglycosylation specificity of a biocatalyst. As proof of concept, sucrose phosphorylase was imprinted with $\alpha$-glucosyl glycerol and subsequently cross-linking with glutaraldehyde. As a result, the enzyme's specificity towards towards glycerol as acceptor was increased by two-fold. Furthermore, the obtained biocatalyst was extremely stable, and could be used for an industrially relevant production process at $60{ }^{\circ} \mathrm{C}$. This convenient procedure thus allows us to simultaneously improve stability and specificity, and could find widespread application in the field of enzyme engineering. 


\section{Acknowledgments}

The authors wish to thank the European Commission and Ghent University for financial support through the FP7-project "Novosides" (grant 265854) and the Multidisciplinary Research Partnership "Ghent Bio-Economy", respectively.

\section{References}

1. Henrissat, B. A classification of glycosyl hydrolases based on amino-acid sequence similarities. Biochem. J. 1991, 280, 309-316.

2. Goedl, C.; Schwarz, A.; Mueller, M.; Brecker, L.; Nidetzky, B. Mechanistic differences among retaining disaccharide phosphorylases: Insights from kinetic analysis of active site mutants of sucrose phosphorylase and alpha,alpha-trehalose phosphorylase. Carbohydr. Res. 2008, 343, 2032-2040.

3. Sprogoe, D.; van den Broek, L.A.M.; Mirza, O.; Kastrup, J.S.; Voragen, A.G.J.; Gajhede, M.; Skov, L.K. Crystal structure of sucrose phosphorylase from bifidobacterium adolescentis. Biochemistry 2004, 43, 1156-1162.

4. Goedl, C.; Sawangwan, T.; Wildberger, P.; Nidetzky, B. Sucrose phosphorylase: A powerful transglucosylation catalyst for the synthesis of alpha-D-glucosides as industrial fine chemicals. Biocatal. Biotransform. 2010, 28, 10-21.

5. Goedl, C.; Sawangwan, T.; Mueller, M.; Schwarz, A.; Nidetzky, B. A high-yielding biocatalytic process for the production of 2-O-( $\alpha$-D-glucopyranosyl)-sn-glycerol, a natural osmolyte and useful moisturizing ingredient. Angew. Chem. Int. Ed. Engl. 2008, 47, 10086-10089.

6. Sawangwan, T.; Goedl, C.; Nidetzky, B. Single-step enzymatic synthesis of (R)-2-O- $\alpha$-D-glucopyranosyl glycerate, a compatible solute from micro-organisms that functions as a protein stabiliser. Org. Biomol. Chem. 2009, 7, 4267-4270.

7. Bornscheuer, U.T. Immobilizing enzymes: How to create more suitable biocatalysts. Angew. Chem.-Int. Ed. 2003, 42, 3336-3337.

8. Aerts, D.; Verhaeghe, T.F.; Roman, B.I.; Stevens, C.V.; Desmet, T.; Soetaert, W. Transglucosylation potential of six sucrose phosphorylases toward different classes of acceptors. Carbohydr. Res. 2011, 346, 1860-1867.

9. Cerdobbel, A.; Desmet, T.; de Winter, K.; Maertens, J.; Soetaert, W. Increasing the thermostability of sucrose phosphorylase by multipoint covalent immobilization. J. Biotechnol. 2010a, 150, 125-130.

10. Cerdobbel, A.; de Winter, K.; Desmet, T.; Soetaert, W. Sucrose phosphorylase as cross-linked enzyme aggregate: Improved thermal stability for industrial applications. Biotechnol. J. 2010b, 5, 1192-1197.

11. Sheldon, R.A. Cross-linked enzyme aggregates as industrial biocatalysts. Org. Process Res. Dev. 2011, 15, 213-223.

12. Cerdobbel, A.; de Winter, K.; Aerts, D.; Kuipers, R.; Joosten, H.-J.; Soetaert, W.; Desmet, T. Increasing the thermostability of sucrose phosphorylase by a combination of sequence- and structure-based mutagenesis. Protein Eng. Des. Sel. 2011, 24, 829-834. 
13. Wildberger, P.; Luley-Goedl, C.; Nidetzky, B. Aromatic interactions at the catalytic subsite of sucrose phosphorylase: Their roles in enzymatic glucosyl transfer probed with Phe(52) $\rightarrow$ Ala and Phe(52) $\rightarrow$ Asn mutants. FEBS Lett. 2011, 585, 499-504.

14. Wiesbauer, J.; Goedl, C.; Schwarz, A.; Brecker, L.; Nidetzky, B. Substitution of the catalytic acid-base glu237 by gln suppresses hydrolysis during glucosylation of phenolic acceptors catalyzed by leuconostoc mesenteroides sucrose phosphorylase J. Mol. Catal. B Enzym. 2009, 65, 24-29.

15. Stahl, M.; Jeppssonwistrand, U.; Mansson, M.O.; Mosbach, K. Induced stereo- and substrate selectivity of bioimprinted alpha-chymotrypsin in anhydrous organic media. J. Am. Chem. Soc. 1991, 113, 9366-9368.

16. Verheyen, E.; Schillemans, J.P.; van Wijk, M.; Demeniex, M.A.; Hennink, W.E.; van Nostrum, C.F. Challenges for the effective molecular imprinting of proteins. Biomaterials 2011, 32, 3008-3020.

17. Vaidya, A.A.; Lele, B.S.; Kulkarni, M.G.; Mashelkar, R.A. Creating a macromolecular receptor by affinity imprinting. J. Appl. Polym. Sci. 2001, 81, 1075-1083.

18. Klein, J.U.; Whitcombe, M.J.; Mulholland, F.; Vulfson, E.N. Template-mediated synthesis of a polymeric receptor specific to amino acid sequences. Angew. Chem.-Int. Ed. 1999, 38, 2057-2060.

19. Peissker, F.; Fischer, L. Crosslinking of imprinted proteases to maintain a tailor-made substrate selectivity in aqueous solutions. Bioorgan. Med. Chem. 1999, 7, 2231-2237.

20. Kaulpiboon, J.; Pongsawasdi, P.; Zimmermann, W. Molecular imprinting of cyclodextrin glycosyltransferases from paenibacillus sp a11 and bacillus macerans with $\gamma$-cyclodextrin. FEBS J. 2007, 274, 1001-1010.

21. Vaidya, A.; Borck, A.; Manns, A.; Fischer, L. Altering glucose oxidase to oxidize D-galactose through crosslinking of imprinted protein. Chembiochem 2004, 5, 132-135.

22. Wang, M.; Qi, W.; Jia, C.; Ren, Y.; Su, R.; He, Z. Enhancement of activity of cross-linked enzyme aggregates by a sugar-assisted precipitation strategy: Technical development and molecular mechanism. J. Biotechnol. 2011, 156, 30-38.

23. Desmet, T.; Soetaert, W. Enzymatic glycosyl transfer: Mechanisms and applications. Biocatal. Biotransform. 2011, 29, doi:10.3109/10242422.2010.548557.

24. Kitao, S.; Yoshida, S.; Horiuchi, T.; Sekine, H.; Kusakabe, I. Formation of kojibiose and nigerose by sucrose phosphorylase. Biosci. Biotechnol. Biochem. 1994, 58, 790-791.

25. Aerts, D.; Verhaeghe, T.; de Mey, M.; Desmet, T.; Soetaert, W. A constitutive expression system for high-throughput screening. Eng. Life Sci. 2011, 11, 10-19.

26. Silverstein, R.; Voet, J.; Reed, D.; Abeles, R.H. Purification and mechanism of action of sucrose phosphorylase. J. Biol. Chem. 1967, 242, 1338-1346.

27. Waffenschmidt, S.; Jaenicke, L. Assay of reducing sugars in the nanomole range with 2,2'-bicinchoninate. Anal. Biochem. 1987, 165, 337-340.

28. Werner, W.; Rey, H.G.; Wielinge, H. Properties of a new chromogen for determination of glucose in blood according to god/pod-method. Z. Anal. Chem. 1970, 252, 224-228.

29. Lowry, O.H.; Rosebrough, N.J.; Farr, A.L.; Randall, R.J. Protein measurement with the foling phenol reagent. J. Biol. Chem. 1951, 193, 265-275. 
30. Cabirol, F.L.; Tan, P.L.; Tay, B.; Cheng, S.; Hanefeld, U.; Sheldon, R.A. Linum usitatissimum hydroxynitrile lyase cross-linked enzyme aggregates: A recyclable enantioselective catalyst. Adv. Synth. Catal. 2008, 350, 2329-2338.

(C) 2012 by the authors; licensee MDPI, Basel, Switzerland. This article is an open access article distributed under the terms and conditions of the Creative Commons Attribution license (http://creativecommons.org/licenses/by/3.0/). 